\title{
Pierre Michon, fictions \& enquêtes, A. Castiglione (dir.)
}

\section{Fabio Scotto}

\section{(2) OpenEdition}

\section{Journals}

\section{Edizione digitale}

URL: http://journals.openedition.org/studifrancesi/10064

DOI: 10.4000/studifrancesi. 10064

ISSN: 2427-5856

\section{Editore}

Rosenberg \& Sellier

\section{Edizione cartacea}

Data di pubblicazione: 1 août 2017

Paginazione: 401-402

ISSN: 0039-2944

\section{Notizia bibliografica digitale}

Fabio Scotto, «Pierre Michon, fictions \& enquêtes, A. Castiglione (dir.)», Studi Francesi [Online], 182 (LXI I II) | 2017, online dal 01 août 2017, consultato il 06 janvier 2021. URL: http://journals.openedition.org/ studifrancesi/10064; DOI: https://doi.org/10.4000/studifrancesi.10064

\section{Questo documento è stato generato automaticamente il 6 janvier 2021}

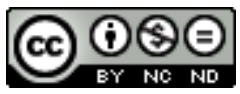

Studi Francesi è distribuita con Licenza Creative Commons Attribuzione - Non commerciale - Non opere derivate 4.0 Internazionale. 


\title{
Pierre Michon, fictions \& enquêtes, A. Castiglione (dir.)
}

\author{
Fabio Scotto
}

\section{NOTIZIA}

Pierre Michon, fictions \& enquêtes, sous la direction de Agnès CASTIGLIONE, Nantes, Éditions Nouvelles Cécile Defaut, 2015, 346 pp.

1 Il volume miscellaneo raccoglie gli atti del Colloque international Pierre Michon: chaos et création tenutosi alla Bibliothèque di Bordeaux il 27, 28, 29 marzo 2014 sotto l'egida dell'ARduA (Association Régionale des diplômés des Universités d'Aquitaine) che ha attribuito nel 2013 la diciannovesima edizione del suo Grand Prix a Pierre Michon.

2 Nell'Avant-propos (pp. 9-13), la curatrice Agnès CASTIGLIONE, da tempo fervente e prolifica studiosa dell'opera di Michon, illustra le piste d'analisi privilegiate, che coprono l'intero percorso dell'opera del narratore, ora attraverso sintesi d'assieme, ora mediante approfondimenti tematici e settoriali più circoscritti dedicati alla sua immaginazione metaforica, alla sua estetica del sublime e dell'eccesso, al metamorfismo della forma e alla ritmica della sua lingua, così come alla varietà delle forme brevi cui ricorre e alle dinamiche finzionali («autobiographie, autofiction, autolégende», «fiction critique»).

3 Apre il volume l'inedito di Pierre Michon Ébauche pour un "David" (pp. 17-22), mirabile esempio di «fiction critique», che pare rimandare alla critica della «déesse Raison. Qui change si souvent de parure» che già fu di Les Onze.

Dei sedici e spesso assai ampi contributi che figurano in sommario, rammentiamo almeno Hommage à Pierre Michon (pp. 23-31) di Jean-Claude M ILNER, che, dopo avere mostrato come i Pastiches proustiani abbiano rivelato con la riproducibilità dello stile per imitazione come esso sia nulla, annovera Michon fra gli «écrivains lucrétiens», che hanno scelto la bella lingua e ne hanno fatto «une machine de guerre contre le style». Ne Le cœur battant des "Onze" (pp. 35-50), Éric VUILLARD analizza il celebre passo dedicato 
al Limousin nel romanzo in questione quale esempio d'ipotiposi che invita il lettore a immedesimarsi nel luogo stesso per discendere nel suo fango e lo fa con uno stilismo critico suggestivo di rara efficacia ed eleganza come per mimesi con lo stile stesso di Michon. Sempre a Les Onze è dedicato l'articolo di Stéphane CHAUDIER Parle-moi de chevaux, de crocodiles et de peinture: cynisme et bestiaire politique dans les "Onze" (pp. 51-80) che si sofferma sul cinismo della risposta storica data da Michon alla mostruosità della ragione rivoluzionaria attraverso la metafora animale, "concretion symbolique» del bestiario politico della quale fornisce sei esempi tratti dal testo (dal cane, associato scatologicamente a Dio, al delfino, alla talpa, al coccodrillo, ai furetti e ai conigli, fino alle mosche e ai cavalli). Ancora su Les Onze il contributo di Claude-Gilbert DuBors (pp. 81-103), in cui la cifra undici è vista come simbolo della mancanza che impedisce al numero di essere cifra tonda, segno di una decapitazione (forse quella del re vittima sacrificale della violenza rivoluzionaria) e di un'irrimediabile incompletezza storica e metafisica, che è anche quella dei Limousins, qui singolarmente ricollegati alla tradizione della canzone popolare che ne descriveva carattere e natura.

Si deve a Faire cuvre: une esthétique de la démesure. Pierre Michon et le sublime (pp. 105-128) di Dominique VIART un'acuta analisi tesa a individuare nell'opera di Michon un'estetica della dismisura riconducibile a taluni campi lessicali e trasversale a più opere, quella di Corentin contrapposta a quella, platonica, di Tiepolo ne Les Onze, che è poi quella del sublime risalente allo Pseudo-Longino, la quale poi approda all'oscenità della dépense batailliana. In Michon forestier (pp. 139-159) Agnès CASTIGLIONE studia la mnemotecnica delle foreste nell'opera di Michon nel solco dell'analisi del modello vegetale di Bachelard. Ne scaturisce un variegato teatro delle origini non privo di richiami epici e ipertestuali. Jean-Claude PINSON (Fragments d'un roman amoureux, pp. 177-190) giustamente rileva la ragione formale e «poéthique» della mancanza di un vero e proprio romanzo nell'opera di Pierre Michon, ovvero il rifiuto del romanzo a profitto della forma breve, e l'impossibilità del romanzo d'amore in quanto l'amore sarebbe di per sé impossibile, secondo un éthos esistenziale liricamente pessimistico che preferisce all'amore stabile del coniugato la pulsione incontrollabile e istantanea dell'amore predatore del celibe, che però trova in una sorta di blues una sua intima esigenza di ritorno ciclico alla ripetizione del ritornello esperienziale.

Completano l'ottimo assieme (e non senza minore qualità di riflessioni e d'esiti, non tutti, per mere ragioni di spazio, qui riassumibili) i contributi di François BERQUIN, Patrick feyler, Maria Teresa gallego URRUtia, Ann JefFerson, Michel prat, Tiphaine SAMOYAULt, Pierre SEnGeS, Frédéric WEST. In appendice un'ampia, aggiornata e ben strutturata «Bibliographie» (pp. 317-344). 